\title{
A Comparison of Batch, Column and Heap Leaching Efficiencies for the Recovery of Heavy Metals from Artificially Contaminated Simulated Soil
}

\author{
Leonard U. Mgbeahuruike', Judith Barrett ${ }^{1}$, Herman J. Potgieter ${ }^{1,2}$, Lizelle van Dyk ${ }^{2}$, \\ Sanja S. Potgieter-Vermaak ${ }^{1,3}$
}

${ }^{1}$ Chemistry and Environmental Science Division, School of Science and the Environment, Manchester Metropolitan University, Manchester, UK

${ }^{2}$ School of Chemical and Metallurgical Engineering, University of the Witwatersrand, Johannesburg, South Africa ${ }^{3}$ Molecular Science Institute, School of Chemistry, University of the Witwatersrand, Johannesburg, South Africa

Email: leonardmgbeahuruike@yahoo.com

How to cite this paper: Mgbeahuruike, L.U., Barrett, J., Potgieter, H.J., van Dyk, L. and Potgieter-Vermaak, S.S. (2019) A Comparison of Batch, Column and Heap Leaching Efficiencies for the Recovery of Heavy Metals from Artificially Contaminated Simulated Soil. Journal of Environmental Protection, 10, 632-650.

https://doi.org/10.4236/jep.2019.105038

Received: January 30, 2019

Accepted: May 20, 2019

Published: May 23, 2019

Copyright $\odot 2019$ by author(s) and Scientific Research Publishing Inc. This work is licensed under the Creative Commons Attribution International License (CC BY 4.0).

http://creativecommons.org/licenses/by/4.0/

\begin{abstract}
This paper shows the effect of three different leaching processes and 4 different leaching agents on the extraction of five metals of interest from an artificially contaminated simulated soil (SS). For the first time, it is shown that these processes and extractants could be compared directly, as the soil was a constant variable. The interest of this study is that the recovery of metals that are of importance in the circular economy, have been demonstrated from an unusual resource, soil. Metal reserves are constantly decreasing worldwide and alternative resources becoming topical. Urban mining of contaminated land and/or waste sites, therefore, becomes an attractive choice for metal extraction/recovery. This study has shown that metal extraction of up to $50 \%$ efficiency could be achieved. Furthermore, EDTA proved to be the best overall extractant when used in batch leaching processes. However, different metals showed preferential recoveries with specific processes and extractants. Therefore the results suggest that the design of a contaminant-specific leaching process performed in a sequential manner could not only leach the metals, but also achieve reasonable separation of the metals.
\end{abstract}

\section{Keywords}

Metals, Leaching, Chelants, Depletion, Extraction, Contaminants, Resource 


\section{Introduction}

Urban mining is becoming more attractive as economically essential metals used for current and future green technologies are rapidly being depleted due to global industrialization and demand [1] [2]. Depletion in this context could imply that the amount of available metals is limited, due to extraction currently being either, economically prohibitive, or technically demanding. For example, copper $(\mathrm{Cu})$ ore, is typically present in the earth's crust as copper-iron-sulphide and copper sulphide minerals, e.g. chalcopyrite $\left(\mathrm{CuFeS}_{2}\right),\left(\mathrm{CuS}_{2}\right)$ [3] [4]. However, reserves are such that, now it is rare to find a large copper deposit averaging more than $1 \%$ or $2 \% \mathrm{Cu}$, making their concentration in an ore body inevitably low [5]. Furthermore, there are predicted shortages in ore reserves for strategic metals playing a significant role in technological progression, thereby making metallurgical process potentially demanding. Numerous scholars in the likes of Keser [1] and Gordon et al. [2] have voiced concern over the availability of the critical metals and their economic and technological importance. However, this shortfall can be overcome by utilizing waste repositories. Studies by Sapsford et al. [6] have shown that many of these metals are present in significant concentrations in the wastes residue amenable to leaching, as well as in contaminated soils [6] [7]. Presently, approximately 2 million potentially polluted sites have been identified in Europe and in the United States, with $40 \%-50 \%$ of these sites [8] impacted with heavy metals. In Sweden alone, more than 80,000 historically contaminated industrial sites have been reported [9]. Research reported steep increases (up to 2040\%) of heavy metals in soils and dumpsites in Nigeria and other African countries [10]. In Ghana, Odai et al. [11] emphatically reported levels of $\mathrm{Cd}$ and $\mathrm{Pb}$ far higher than the WHO/FAO recommended values. Contrary to past practices of simply remediating soils, this figure, although of environmental concern, offers a potential "resource hub" for future recovery. The recovery of metal resources from secondary sources is regarded as a beneficial approach, extending the efficient use of metals [12], reducing pressure on virgin resources [1] [13] and resulting in major energy savings relative to the level of energy inputs required to produce metals from primary sources [14]. The effectiveness of any recovery process is usually characterized by the ability of the chemical reagent to potentially solubilize and extract the elements bound in, or associated with, a particular soil phase. This is commonly simulated in the laboratory through dynamic (column and heap) and static (batch) [15] [16] studies.

In static studies, mixtures are vigorously stirred during the entire reaction time to enhance homogeneity and reactivity. This method has been noted for its ease of operation and provides qualitative predictive information on the leaching behaviour of metals from the soil matrix [17] [18] on a larger scale. However, the efficiency of the batch approach is somewhat compromised because the soils are often subjected to excessive mobilization of dissolved organic carbon and/or colloids that is uncharacteristic of field scenarios [19] [20]. Dynamic studies involve a percolation process that is characterized by a continuous flow of liquid through a fixed bed of feedstock (soil), invariably presents a better simulation to 
a leaching process, that occur under field conditions [21] [22].

In this study, two dynamic (column and heap) leaching systems, as well as a batch system, are used as potential techniques to investigate the leaching of heavy metal from polluted simulated soil (SS) with various organic solvents. We have reported in Potgieter-Vermaak et al. [23] what the influence on leaching profiles of synthetically contaminated individual soil components and its composite (a simulated soil) are, using a batch approach. The objective of this investigation is to evaluate metal leaching behaviour as influenced by the selected extractants (EDTA $\left(\mathrm{C}_{10} \mathrm{H}_{14} \mathrm{~N}_{2} \mathrm{O}_{8} \mathrm{Na}_{2} \cdot \mathrm{H}_{2} \mathrm{O}\right)$; Citric acid $\left(\mathrm{CA}-\left(\mathrm{CH}_{2}\right)_{2}(\mathrm{COOH})_{3} \mathrm{COH}\right)$; EDDS $\left(\mathrm{C}_{10} \mathrm{H}_{16} \mathrm{~N}_{2} \mathrm{O}_{8}\right)$; Acetylacetone (Hacac- $\left.\mathrm{C}_{5} \mathrm{H}_{8} \mathrm{O}_{2}\right)$ ), the process of leaching (batch, column or heap) and the combined interactive effects of these two factors. These findings will feed into the third phase of this investigation, during which the processes will be applied to industrially impact environmental samples, to evaluate its use as predictive tool.

\section{Experimental}

\subsection{Chemicals and Materials}

To minimise variabilities associated with heterogeneity in the real soil scenario during this comparative study, use was made of a simulated soil (SS), consisting of kaolinite clay (KC), peat moss (PM) and quartz sand (QS) (all sourced from local shops) mixed in a ratio of 70:20:10 for a QS:BC:PM ratio prepared according to the "recipe" described in the guidelines of the Organization for Economic Cooperation and Development (OECD) [24] [25]. The reference soil was composed of the following: Bentonite, $20 \%$; quartz sand, $70 \%$; peat moss, $10 \%$. OECD soil may not exactly mimic the behaviour of a natural soil; however, it was used as a simple model. The SS was contaminated with $\mathrm{Cd}, \mathrm{Cu}, \mathrm{Ni}, \mathrm{Pb}$ and $\mathrm{Zn}$ atomic absorption standard solutions $\left(1000 \mathrm{mg} \cdot \mathrm{dm}^{-3}\right)$ purchased from Sigma Aldrich. Leaching agents: EDTA $\left(\mathrm{C}_{10} \mathrm{H}_{14} \mathrm{~N}_{2} \mathrm{O}_{8} \mathrm{Na}_{2} \cdot \mathrm{H}_{2} \mathrm{O}\right)$, Citric acid (CA- $\left.\left(\mathrm{CH}_{2}\right)_{2}(\mathrm{COOH})_{3} \mathrm{COH}\right)$; EDDS $\left(\mathrm{C}_{10} \mathrm{H}_{16} \mathrm{~N}_{2} \mathrm{O}_{8}\right)$; Acetylacetone (Hacac- $\left.\mathrm{C}_{5} \mathrm{H}_{8} \mathrm{O}_{2}\right)$; were purchased from Sigma Aldrich, Innospec and Alfa Aeser. All mineral acids used in the analysis were of analytical or spectral grade.

\subsection{Experimental Methods}

The SS was analysed for its physical and chemical properties, using standard techniques and approaches. In a nutshell, the total organic carbon (TOC), $\mathrm{pH}$, cation exchange capacity (CEC), specific surface area (SSA), particle size distribution, mineralogy, and baseline metal profile were determined as described in Potgieter-Vermaak [23]. All metal concentrations were determined by ICP-OES and sample concentrations were corrected for matrix effects by procedural blanks, normalized to sample mass and reported as $\mathrm{mg} \cdot \mathrm{kg}^{-1}$ dry weight. A 4-point calibration (plus blank) was undertaken using a multi-element standard solution $\left(100 \mathrm{mg} \cdot \mathrm{dm}^{-3}\right)$ which was matrix-matched for each calibration curve. This yielded a calibration coefficient of $\geq 0.9995$ for each of the concentration of 
the metals analysed. The LOD for the ICP-OES according to the analysed elements were $\mathrm{Cd}$ (0.0001), $\mathrm{Cu}$ (0.0022), $\mathrm{Ni}(0.0009), \mathrm{Pb}(0.0008)$, and $\mathrm{Zn}(0.0027) \mathrm{mg} \cdot \mathrm{dm}^{-3}$.

\subsection{Experimental Methodology}

\subsubsection{Contamination Protocol}

Accurately weighed $(20 \mathrm{~g} \pm 0.0005 \mathrm{~g})$ SS was contaminated with a multi-metal (MM) solution containing $\mathrm{Cd}, \mathrm{Cu}, \mathrm{Ni}, \mathrm{Pb}$ and $\mathrm{Zn}$ of concentrations 50, 570, 650, $1590,2160 \mathrm{mg} \cdot \mathrm{kg}^{-1}$, respectively. These concentrations are three times the intervention values set as regulatory limits by the Department of Petroleum Resources in Nigeria [26]. The motivation behind these concentrations was to simulate heavily contaminated land in Nigeria, with the specific aim of showing the potential of the 3 methods of washing/leaching and the 4 leaching agents, discussed further on in this paper, to remediate the soil and recover the metals of interest in an economically sustainable way. The metals investigated in this study were chosen based on their potential to generate revenue when recovered, as well as their toxicity potential to both the environment and humans. SS was used is to minimise the variability that a natural or industrially impacted soil will create in the data set so that the data could be used as predictive tool. The MM loading achieved was $96 \% \pm 2.37 \%$.

\subsubsection{Batch Leaching Test}

A standard batch leaching test at liquid-to-solid ratio (L/S) of 10:1 was used to determine the leaching potential of the metals in the contaminated SS. For this purpose, $20 \mathrm{~g} \pm 0.0003 \mathrm{~g}$ of dried contaminated SS was accurately weighed in triplicate and placed in three different polypropylene tubes of $500 \mathrm{~cm}^{3}$ capacity containing $200 \mathrm{~cm}^{3}$ of leaching solution (EDTA at $0.034 \mathrm{mold} \cdot \mathrm{m}^{-3}$ or EDDS at $0.034 \mathrm{mold} \cdot \mathrm{m}^{-3}$ or Hacac at $3.0 \mathrm{mold} \cdot \mathrm{m}^{-3}$ or CA at $0.026 \mathrm{mold} \cdot \mathrm{m}^{-3}$ ) maintaining a solid/liquid ratio of 1:10. These concentrations ensured an excess of extractant. The change in $\mathrm{pH}$ upon exposure to the leaching agent was monitored. The mixtures were agitated with the use of a horizontal shaker for 30, 60, 90, 120 and 150 minutes after which it was centrifuged for 15 minutes at $3000 \mathrm{rpm}$. A procedural blank was carried out by using deionized water as extractant on all substrates, to determine the contribution of the respective leaching agents. The $\mathrm{pH}$ of the supernatant was measured after 150 min of contact time to establish any changes therein. After each run, an aliquot of the supernatant $\left(1 \mathrm{~cm}^{3}\right)$ solution was filtrated with a syringe filter $(0.45 \mu \mathrm{m})$ into a plastic vial of $15 \mathrm{~cm}^{3}$ capacity and later made up to $10 \mathrm{~cm}^{3}$ with deionized water (or industrial methylated spirit in the case of Hacac). Subsequently, the filtrates were analysed by ICP-OES and the selected metal concentrations retained in the adsorbent phase ( $\left.\mathrm{mg}^{\mathrm{kg}} \mathrm{kg}^{-1}\right)$ were calculated. The percentage of metal leached from the soil was calculated using Equation (1).

$$
\% \text { metal leached }=\frac{\text { mass ofmetal in supernatant }}{\text { mass of metal originally loaded on substrate }} \times 100
$$


To ensure repeatability, this procedure was carried out in triplicate. Procedural blanks and matrix-matched standards ensured rigorous QA and QC.

\subsubsection{Column Leaching Test}

To compare the in-situ leaching with a dynamic process, a column leaching approach was used. For this purpose, a glass chromatographic column (dimensions: Internal diameter $2 \mathrm{~cm}$ and $30 \mathrm{~cm}$ in height) with a sintered disc frit was used, so that the flow rate could be controlled. Preliminary experimental set-ups were tried and tested (not shown here) and a preferred set-up (not shown here) delivered the best results. The soil was packed using a slurry technique as is customary for chromatographic column packing as this enabled the most uniform packing and would be the more convenient method to use in a plant operation also. The SS was sandwiched between two layers of sand $(0.5 \mathrm{~cm}$ each). The sand bed on the frit was to ensure no clogging or loss of sample and at the top it ensured that the introduction of the sample did not disturb the soil bed. The SS column volume was $8 \mathrm{~cm}$. By gently tapping the column with a rubber rod uniform packing was ensured, thereby minimising any band broadening effect. After packing, the column head was brought to a minimum before the leaching agent (EDTA, EDDS, Hacac, CA) was introduced. The leaching agent was introduced using a separating funnel as a reservoir and ahead of $10 \mathrm{~cm}^{3}$ was maintained by regulating the flow rate of the separating funnel and synchronising it with that of the column. The flow rate was maintained at $0.8 \mathrm{~cm}^{3} \cdot \mathrm{min}^{-1}$. The leachate was collected every 30 minutes over a total leaching time of 150 minutes and the volume measured to the nearest $0.5 \mathrm{~cm}^{3}$. The $\mathrm{Cd}, \mathrm{Cu}, \mathrm{Ni}, \mathrm{Pb}$, and $\mathrm{Zn}$ concentrations leached from the SS by the different leaching agents were determined using ICP-OES as described elsewhere, after the $\mathrm{pH}$ of the leachate was measured. Each extractant was run in triplicate.

\subsubsection{Heap Leaching Test}

Heap leaching, as a dynamic process, was also considered for comparison to the column and in-situ leaching methods. This involves stacking of metal-bearing soil into a heap on an impermeable pad, irrigating it with a chemical solution for an extended period to dissolve the preferred metals, and collecting the leachate as it percolates from the base of the heap [27] [28]. However, in order to mimic this approach for a laboratory study, the heap configuration was simulated in a heap set up (not shown here) to achieve a dynamic leaching process. The set-up involved, a perforated Buchner funnel $(70 \mathrm{~mm})$ with a filter paper $(0.45 \mathrm{um})$ was used to basically contain the heap and facilitate collection of the leachate over time for metal analysis. The irrigation was affected using a watering can rose of which some of the perforations were blocked to control the flow rate. The supply of extractants to the rose was ensured by a continuous flow from a reservoir, for which a $250 \mathrm{ml}$ separating funnel has been used.

The Buchner funnel was charged with $20 \mathrm{~g} \pm 0.0004 \mathrm{~g}$ of soil and then irrigated with the different chelating agents described elsewhere. An average flow rate under gravity of $11.2 \mathrm{~cm}^{3} \cdot \mathrm{min}^{-1}$ was maintained and the leachate collected 
over time $(30,60,90,120$, and $150 \mathrm{~min})$. The leachate was analysed for $\mathrm{Cd}, \mathrm{Cu}$, $\mathrm{Ni}, \mathrm{Pb}$, and $\mathrm{Zn}$. Each extractant run was done in triplicate. The $\mathrm{pH}$ measurements of the leachate samples were taken before metal analysis on the ICP-OES.

\section{Results and Discussions}

\subsection{SS Characteristics}

The ultimate goal of the work reported here is to use artificially contaminated simulated soil (SS) of known composition as a model to determine leaching efficiencies of impacted environmental samples. The following pedological properties of the SS used in the experiment were: specific surface area (SSA) $9.8 \mathrm{~m}^{2} / \mathrm{g}$, organic matter 14\%, $\mathrm{pH} 9.44$, cation exchange capacity (CEC) 19 meq. $100 \mathrm{~g}^{-1}$. The morphology of SS appear to be light grey in colour, with colour notation of $2.5 \mathrm{Y} 7 / 2$ as described by [29] and can be classed as sandy loam. The soil contained $0.2 \pm 0.1 \mathrm{mg} \cdot \mathrm{kg}^{-1} \mathrm{Cd}, 9.6 \pm 1.1 \mathrm{mg} \cdot \mathrm{kg}^{-1} \mathrm{Cu}, 1.7 \pm 0.7 \mathrm{mg} \cdot \mathrm{kg}^{-1} \mathrm{Ni}, 12.4 \pm 0.1$ $\mathrm{mg} \cdot \mathrm{kg}^{-1} \mathrm{~Pb}$ and $55 \pm 2.4 \mathrm{mg} \cdot \mathrm{kg}^{-1} \mathrm{Zn}$. The measured values were compared with those reported for natural soils in literature. The measured $\mathrm{pH}, \mathrm{CEC}$ and organic matter are similar to those reported by Chen [30]; Sun [31] and Koleli and Demir [32] reporting 9.6, $17.6 \mathrm{meq} \cdot 100 \mathrm{~g}^{-1}$ and 18\%, respectively. By contrast, the value of SSA as reported by Kovo et al. [33] was significantly higher (55.8 $\mathrm{m}^{2} / \mathrm{g}$ ) than that measured for SS. Montmorillonite and quartz were identified as the dominant minerals in the SS sample but the presence of additional minerals were identified using micro Raman spectroscopy, which may influence the metal leaching. The trace metal concentrations contained in the SS were considerably below the threshold values of the Department of Petroleum Resources [26] Nigeria. The degree of metal contamination was in the descending order $\mathrm{Zn} \gg$ $\mathrm{Cu}>\mathrm{Pb}>\mathrm{Ni} \gg \mathrm{Cd}$. Zn was present in a much higher concentration (140 compared to $0.2,9.6,1.7$, and $12.4 \mathrm{mg} \cdot \mathrm{kg}^{-1}$ for $\mathrm{Cd}, \mathrm{Cu}, \mathrm{Ni}$, and $\mathrm{Pb}$, respectively) and higher than that reported in literature for natural soils [31].

\subsection{Batch Process}

The leaching behaviour of the 5 metals of interest was investigated by subjecting the solid SS sample to an in-situ leaching process that is characteristic of a batch configuration. The leaching trend for these metals was monitored over leaching time intervals of $30,60,90,120$, and 150 min using selected extractants (EDTA, EDDS, Hacac and CA). The results (indicating the mass of metal per kg SS extracted after $150 \mathrm{~min}$, as well as the \% extraction efficiency for each metal) are summarised in Table 1 . From the data it is evident that specific metals reported different extraction efficiencies across the 4 extractants investigated.

For Cd the order of leaching efficiency was EDTA $=\mathrm{CA}>$ EDDS $\gg \mathrm{Hacac}$, with an average efficiency of $24.4 \%$ (range: 34.6 - 4.4). EDTA and CA leached the most $\mathrm{Cd}\left(17 \mathrm{mg} \cdot \mathrm{kg}^{-1}\right)$, followed by EDDS (12 $\left.\mathrm{mg} \cdot \mathrm{kg}^{-1}\right)$ and Hacac $(2.1$ $\left.\mathrm{mg} \cdot \mathrm{kg}^{-1}\right)$. EDTA and EDDS are strong chelating agents that form multidentate ligands with metal cations. It is expected that molecules with more carboxyl groups have higher extracting capacity than a molecule with fewer carboxyl 
Table 1 . Extractability of $\mathrm{Cd}, \mathrm{Cu}, \mathrm{Ni}, \mathrm{Pb}$, and $\mathrm{Zn}$ in artificially contaminated $\mathrm{SS}$ by a batch extraction with selected extractants. The standard deviation on the values reported are in the range $\pm(0.03-3.05)(\mathrm{n}=3)$.

\begin{tabular}{ccccccccc}
\hline Metal & \multicolumn{2}{c}{ EDTA } & \multicolumn{2}{c}{ EDDS } & \multicolumn{2}{c}{ Hacac } & \multicolumn{2}{c}{ CA } \\
\hline $\begin{array}{c}\text { (loading } \\
\left.\mathrm{mg} \cdot \mathrm{kg}^{-1}\right)\end{array}$ & $\begin{array}{c}\mathrm{mg} \cdot \mathrm{kg}^{-1} \\
\text { leached }\end{array}$ & $\begin{array}{c}\% \\
\text { efficiency }\end{array}$ & $\begin{array}{c}\mathrm{mg} \cdot \mathrm{kg}^{-1} \\
\text { leached }\end{array}$ & $\begin{array}{c}\% \\
\text { efficiency }\end{array}$ & $\begin{array}{c}\mathrm{mg} \cdot \mathrm{kg}^{-1} \\
\text { leached }\end{array}$ & $\begin{array}{c}\% \\
\text { efficiency }\end{array}$ & $\begin{array}{c}\mathrm{mg} \cdot \mathrm{kg}^{-1} \\
\text { leached }\end{array}$ & $\begin{array}{c}\% \\
\text { efficiency }\end{array}$ \\
\hline $\mathrm{Cd}(50)$ & 17.0 & 34.5 & 12.0 & 24.1 & 2.1 & 4.4 & 17.0 & 34.6 \\
$\mathrm{Cu}(550)$ & 204.6 & 37.9 & 131.6 & 28.9 & 226.8 & 41.8 & 66.5 & 11.7 \\
$\mathrm{Ni}(650)$ & 227.7 & 37.3 & 88.4 & 16.4 & 215.1 & 36.7 & 97.9 & 18.1 \\
$\mathrm{~Pb}(1590)$ & 702.1 & 45.4 & 207.0 & 13.1 & 30.1 & 1.9 & 150.2 & 10.3 \\
$\mathrm{Zn}(2160)$ & 567.7 & 26.9 & 129.8 & 6.0 & 327.0 & 16.4 & 356.2 & 18.2 \\
\hline
\end{tabular}

groups [34], which could explain the higher efficiency for EDTA and CA (four and three carbonyl groups, respectively). However, this would suggest that EDDS (4 carbonyl groups) should behave similar to the EDTA, which is not the case (12 mg. $\mathrm{kg}^{-1}$ ). This phenomenon could partly be attributed to the influence of acid dissolution in the CA. CA will reduce soil $\mathrm{pH}$ (by releasing hydrogen ions by substitution and forming soluble complexes by a complexation reaction) [35]. In our study, we have shown that CA lowered the $\mathrm{pH}$ to 3.64 in comparison to 5.45 and 5.54 by EDTA and EDDS respectively. [36] and [37] also reported a higher extraction efficiency for Cd during the application of CA and EDTA. In addition, higher mobilisation of targeted metals is observed for EDTA than EDDS [38] [39]. The effectiveness is related (or part related) to the fact that the metal complexes with EDDS are somewhat lower in stability than the corresponding complexes with EDTA.

For $\mathrm{Cu}$ the order of extraction efficiency was completely different to that of $\mathrm{Cd}$ (Hacac $>$ EDTA $>$ EDDS > CA; with an average efficiency of $30.1 \%$ and a range of $41.8 \%$ to $11.7 \%)$. The Hacac leached the highest amount of $\mathrm{Cu}(226.8$ $\left.\mathrm{mg} \cdot \mathrm{kg}^{-1}\right)$, followed by EDTA (204 mg. $\mathrm{kg}^{-1}$ ) and EDDS (131 mg. $\left.\mathrm{kg}^{-1}\right)$. CA leached only $65 \mathrm{mg} \cdot \mathrm{kg}^{-1}$ of $\mathrm{Cu}$. The high extraction of $\mathrm{Cu}$ leached by Hacac over other extractants was observed before [23] and was expected, as Hacac is known to preferentially form complexes with $\mathrm{Cu}$ ion [40]. Cu mobilisation by EDDS was significantly lower than what was observed for EDTA, even though EDTA ( $\log K=18.8)$ is about similar to EDDS ( $\log K=18.4$ ) (Table 2). According to [41], the metal complexes with EDDS are somewhat lower in stability than the corresponding complexes with EDTA. This phenomenon could be attributed to the dissociative tendency of CuEDDS to exchange its metal in the complex and readsorb onto the soil surface [42].

The Ni had a very similar profile to $\mathrm{Cu}$ and only differed slightly in that the EDDS and CA exchanged places in the order of extraction efficiency. The average extraction efficiency percentage for $\mathrm{Ni}$ was $27.1 \%$ (37.3 - 16.4). EDTA leached the highest $\left(227.7 \mathrm{mg} \cdot \mathrm{kg}^{-1}\right)$, followed by Hacac $\left(215.1 \mathrm{mg} \cdot \mathrm{kg}^{-1}\right)$ and CA (97.9 $\left.\mathrm{mg} \cdot \mathrm{kg}^{-1}\right)$. Surprisingly, EDDS $\left(88.4 \mathrm{mg} \cdot \mathrm{kg}^{-1}\right)$ leached the least.

In contrast $\mathrm{Pb}$ had the profile EDTA $\gg \mathrm{EDDS} \approx \mathrm{CA} \gg$ Hacac with an 
Table 2. Complexation formation constants (Log $K_{\mathrm{ML}}$ ) with cations [42] [43] [44] [45] [46].

\begin{tabular}{cccccc}
\hline \multirow{2}{*}{ Chelant } & \multicolumn{5}{c}{$\log K_{\mathrm{ML}}\left(\mathrm{T}=25^{\circ} \mathrm{C}, \mathrm{I}=0.1 \mathrm{M}\right)$} \\
\cline { 2 - 6 } & $\mathrm{Cd}$ & $\mathrm{Cu}$ & $\mathrm{Ni}$ & $\mathrm{Pb}$ & $\mathrm{Zn}$ \\
\hline EDTA & 16.5 & 18.8 & 20.1 & 18.8 & 17.5 \\
EDDS & 10.8 & 18.4 & 16.8 & 12.7 & 13.4 \\
Hacac & nd & 8.2 & 5.5 & nd & nd \\
CA & 4.0 & 5.9 & 6.6 & 4.1 & 6.2 \\
\hline
\end{tabular}

${ }^{*}$ nd: Not determined.

average of $17.7 \%$ and a range of 45.4 to 1.9 . EDTA $\left(702 \mathrm{mg} \cdot \mathrm{kg}^{-1}\right)$ leached the most followed by EDDS (207 $\left.\mathrm{mg} \cdot \mathrm{kg}^{-1}\right)$ and CA (150 mg. $\left.\mathrm{kg}^{-1}\right)$ with Hacac (30 $\mathrm{mg} \cdot \mathrm{kg}^{-1}$ ) leaching the least. EDTA extracted between 4 times and 20 times as much as the rest of the extractants. This result was to be expected due to the much stronger complexation of PbEDTA compared to other metal complexing extractants [43].

Finally, $\mathrm{Zn}$ displayed a profile that was similar to Cd but the EDTA extracted $\mathrm{Zn}$ about 1.5 times better than CA and the Hacac and EDDS arbitrarily changed places. The average extraction efficiency was $16.8 \%$ and ranged from $26.9 \%$ to $6.0 \%$.

It is further noted from Table 1, that overall, EDTA outperformed the other extractants and average efficiency of $36.4 \pm 6.7$ was calculated across the 5 metals of interest. The other extractants had similar efficiencies overall $(20.2 \%, 18.6 \%$, $17.7 \%$ for Hacac, CA and EDDS, respectively). However, the extraction behaviour observed indicated a possibility to recover certain metals, using sequential extraction approaches, due to preferential leaching. For example, $\mathrm{Cu}$ and $\mathrm{Ni}$ can be separated from the rest using Hacac because of their structure, acidic properties and ability to form complexes [40]. This can be followed by a CA leach which will preferentially remove $\mathrm{Cd}$. $\mathrm{The} \mathrm{Pb}$ and $\mathrm{Zn}$ can then be separated from the matrix by an EDTA leach.

\subsection{Column Leaching}

In-situ extraction leaching was performed on SS by using column approach and a solid liquid ratio of 1:10 to investigate the extraction of the metal species of interest. To illustrate the elution trends, the leaching concentrations $\left(\mathrm{mg} \cdot \mathrm{kg}^{-1}\right)$ of metals from SS after 30, 60, 90, 120, and 150 minutes contact time with extractants (EDTA, EDDS, Hacac and CA) were chosen. The results (indicating the mass of metal per $\mathrm{kg}$ SS extracted after $150 \mathrm{~min}$, as well as the \% extraction efficiency for each metal) are summarised in Table 3. From the data, it is evident that specific metals reported different extraction efficiencies across the 4 extractants investigated.

For Cd the order of leaching efficiency was different to the batch study: EDTA $\approx$ EDDS $>$ CA $>$ Hacac, with an average efficiency of $19.8 \%$ (23.8 - 12.4) which is significantly lower than what was observed for the batch process. EDTA and EDDS leached the most Cd (11.9 mg. $\left.\mathrm{kg}^{-1}\right)$, followed by CA $\left(10.2 \mathrm{mg} \cdot \mathrm{kg}^{-1}\right)$ and Hacac $\left(6.2 \mathrm{mg} \cdot \mathrm{kg}^{-1}\right)$. 
Table 3. Extractability of $\mathrm{Cd}, \mathrm{Cu}, \mathrm{Ni}, \mathrm{Pb}$, and $\mathrm{Zn}$ in artificially contaminated $\mathrm{SS}$ by a column extraction with selected extractants. The standard deviation on the values reported are in the range $\pm(0.37-2.62)(n=3)$.

\begin{tabular}{ccccccccc}
\hline Metal & \multicolumn{2}{c}{ EDTA } & \multicolumn{2}{c}{ EDDS } & \multicolumn{2}{c}{ Hacac } & \multicolumn{2}{c}{ CA } \\
\hline $\begin{array}{c}\text { loading } \\
\left(\mathrm{mg}_{\mathrm{kg}}{ }^{-1}\right)\end{array}$ & $\begin{array}{c}\mathrm{mg} \mathrm{kg}^{-1} \\
\text { leached }\end{array}$ & $\begin{array}{c}\% \\
\text { efficiency }\end{array}$ & $\begin{array}{c}\mathrm{mg} \cdot \mathrm{kg}^{-1} \\
\text { leached }\end{array}$ & $\begin{array}{c}\% \\
\text { efficiency }\end{array}$ & $\begin{array}{c}\mathrm{mg} \cdot \mathrm{kg}^{-1} \\
\text { leached }\end{array}$ & $\begin{array}{c}\% \\
\text { efficiency }\end{array}$ & $\begin{array}{c}\mathrm{mg}^{\mathrm{k}} \mathrm{kg}^{-1} \\
\text { leached }\end{array}$ & $\begin{array}{c}\% \\
\text { efficiency }\end{array}$ \\
\hline $\mathrm{Cd}(50)$ & 11.9 & 23.8 & 11.3 & 22.6 & 6.2 & 12.4 & 10.2 & 20.4 \\
$\mathrm{Cu}(550)$ & 114.4 & 20.8 & 110.7 & 20.1 & 97.3 & 17.7 & 95.1 & 17.3 \\
$\mathrm{Ni}(650)$ & 290.4 & 44.7 & 307.2 & 47.3 & 248.9 & 38.3 & 174.6 & 26.9 \\
$\mathrm{~Pb}(1590)$ & 211.5 & 13.3 & 173.1 & 10.9 & 51.2 & 3.2 & 807.7 & 50.8 \\
$\mathrm{Zn}(2160)$ & 397.2 & 18.4 & 389.0 & 18.0 & 231.3 & 10.7 & 355.3 & 16.4 \\
\hline
\end{tabular}

$\mathrm{Cu}$ leaching data showed very little difference between the extractants, with Hacac and CA reporting slightly lower extraction efficiencies and significantly different from the batch process as presented in Table 3 . The leaching efficiency was observed to follow the order EDTA $\approx$ EDDS $>$ Hacac $\approx$ CA with an average efficiency of $19.0 \%(20.8-17.3)$. EDTA and EDDS leached $114.4 \mathrm{mg} \cdot \mathrm{kg}^{-1}$ and Hacac $\left(97.3 \mathrm{mg} \cdot \mathrm{kg}^{-1}\right)$.

For $\mathrm{Ni}$, extraction efficiency differed considerably from $\mathrm{Cd}$ and $\mathrm{Cu}$ and was observed to follow the order EDDS $\approx$ EDTA $>$ Hacac $>$ CA, with an average efficiency of $39.3 \%$ (47.3 - 26.9), which was much higher than the batch process average. EDDS leached $307.2 \mathrm{mg} \cdot \mathrm{kg}^{-1}$ and CA $174.6 \mathrm{mg} \cdot \mathrm{kg}^{-1}$.

For $\mathrm{Pb}$, extraction efficiency was in the order of CA $\gg$ EDTA $>$ EDDS > Hacac, with an average efficiency similar to the batch process of $19.6 \%$ (50.8 3.2). CA ( $\left.807.7 \mathrm{mg} \cdot \mathrm{kg}^{-1}\right)$ leached the most, followed by EDTA $\left(211.5 \mathrm{mg} \cdot \mathrm{kg}^{-1}\right)$ and EDDS (173.1 $\left.\mathrm{mg} \cdot \mathrm{kg}^{-1}\right)$ with Hacac $\left(51.2 \mathrm{mg} \cdot \mathrm{kg}^{-1}\right)$ leaching the least.

$\mathrm{Zn}$ displayed a leaching profile that was similar to $\mathrm{Cu}$ however, CA leached $\mathrm{Zn}$ much better than Hacac and as such, extraction efficiency followed the order $\mathrm{EDTA} \approx \mathrm{EDDS} \approx \mathrm{CA}>\mathrm{Hacac}$, with an average efficiency similar to the batch process of $15.9 \%(18.4-10.7)$. EDTA $\left(397.2 \mathrm{mg} \cdot \mathrm{kg}^{-1}\right)$ leached the most with Hacac $\left(231.3 \mathrm{mg} \cdot \mathrm{kg}^{-1}\right)$ leaching the least.

Overall, the extraction efficiencies of EDTA, EDDS and CA $(24 \pm 12 ; 24 \pm 13$; $26 \% \pm 14 \%$, respectively) across the 5 metals of interest, were nearly double that of Hacac $(16 \% \pm 13 \%)$. The data suggest specificity of the metals for extractant as well as process, if we compare it with the batch process. For example, CA extraction of $\mathrm{Pb}$ with the batch process was only $10.5 \%$ effective, but with the column process the extraction efficiency was 5 times higher and outperformed the highest extraction efficiency for Pb obtained by the batch process (EDTA at $45 \%)$. On the other hand, Cd showed similar extraction efficiencies with EDTA and CA, but extraction in the batch process was 1.5 times higher, indicating that the process plays a role in the efficiency. These findings, therefore, suggest that these metals may be removed from contaminated soil, using a battery of processes and different extractants. 


\subsection{Heap Leaching}

To further compare a dynamic perculating process with the batch process, reported in 3.2, a heap leaching experiment with a solid liquid ratio of 1:10 were used to investigate the leaching behaviour of $\mathrm{Cd}, \mathrm{Cu}, \mathrm{Ni}, \mathrm{Pb}$, and $\mathrm{Zn}$ bound to $\mathrm{SS}$ as well. As before, the elution profile over time (30, 60, 90, 120, and 150 minutes) was monitored with the selected extractants (EDTA, EDDS, Hacac, and CA). The results (indicating the mass of metal per kg SS extracted after $150 \mathrm{~min}$, as well as the \% extraction efficiency for each metal) are summarised in Table 4. It was observed that the specific metals reported considerably different extraction efficiencies across the four extractants examined.

For Cd, the leaching efficiency followed the order EDTA $\approx$ EDDS $>\mathrm{CA}>\mathrm{Ha}$ cac, with an average efficiency of $36.3 \%(48.2-21.4)$ across all extractants, exceeding both previous processes by 33 and $46 \%$. EDTA and EDDS leached the most $\left(24.1 \mathrm{mg} \cdot \mathrm{kg}^{-1}\right)$, followed by CA $\left(16.2 \mathrm{mg} \cdot \mathrm{kg}^{-1}\right)$ and Hacac $\left(10.7 \mathrm{mg} \cdot \mathrm{kg}^{-1}\right)$. The data suggests, as seen for the column leaching, that $\mathrm{Cd}$ extraction is mainly driven by the process, with heap leaching outperforming the other two processes.

For $\mathrm{Cu}$, the extraction efficiency was similar to the batch process, with $\mathrm{Ha}$ cac $>$ EDTA $\approx$ EDDS > CA but with a lower average efficiency of $20.6 \%$ (28.7 15.4). Hacac leached the most (157.7 $\mathrm{mg} \cdot \mathrm{kg}^{-1}$ and CA the least $\left(84.6 \mathrm{mg} \cdot \mathrm{kg}^{-1}\right)$. Based on formation constants, this result is unexpected (Table 2). The enhanced $\mathrm{Cu}$ extraction efficiency by Hacac is only observed for the batch and heap leaching processes. Therefore, it seems as though the process again plays a significant role in the recovery of the metals.

Contrary to the other processes, the Ni extraction efficiency was in the order Hacac $>$ EDTA $\approx$ EDDS $>\mathrm{CA}$, similar to the $\mathrm{Cu}$, with an average efficiency of $27 \%$ (30.5 - 22.4). There was, however, not a big difference in the efficiency of the Hacac, EDTA, and EDDS. Hacac $\left(198.2 \mathrm{mg} \cdot \mathrm{kg}^{-1}\right)$ leached the most and CA leaching the least $\left(145.7 \mathrm{mg} \cdot \mathrm{kg}^{-1}\right)$ in terms of normalized values. The effectiveness of the three leaching agents, Hacac, EDTA and EDDS, is seemingly not

Table 4. Extractability of $\mathrm{Cd}, \mathrm{Cu}, \mathrm{Ni}, \mathrm{Pb}$, and $\mathrm{Zn}$ in artificially contaminated SS by a heap extraction with selected extractants. The standard deviation on the values reported are in the range $\pm(1.35-5.69)(n=3)$.

\begin{tabular}{ccccccccc}
\hline Metal & \multicolumn{2}{c}{ EDTA } & \multicolumn{2}{c}{ EDDS } & \multicolumn{2}{c}{ Hacac } & \multicolumn{2}{c}{ CA } \\
\hline $\begin{array}{c}\text { loading } \\
\left(\mathrm{mg}^{\mathrm{kg}} \mathrm{kg}^{-1}\right)\end{array}$ & $\begin{array}{c}\mathrm{mg} \cdot \mathrm{kg}^{-1} \\
\text { leached }\end{array}$ & $\begin{array}{c}\% \\
\text { efficiency }\end{array}$ & $\begin{array}{c}\mathrm{mg} \cdot \mathrm{kg}^{-1} \\
\text { leached }\end{array}$ & $\begin{array}{c}\% \\
\text { efficiency }\end{array}$ & $\begin{array}{c}\mathrm{mg} \cdot \mathrm{kg}^{-1} \\
\text { leached }\end{array}$ & $\begin{array}{c}\% \\
\text { efficiency }\end{array}$ & $\begin{array}{c}\mathrm{mg} \cdot \mathrm{kg}^{-1} \\
\text { leached }\end{array}$ & $\begin{array}{c}\% \\
\text { efficiency }\end{array}$ \\
\hline $\mathrm{Cd}(50)$ & 24.1 & 48.2 & 21.5 & 43.0 & 10.7 & 21.4 & 16.2 & 32.4 \\
$\mathrm{Cu}(550)$ & 104.5 & 19.2 & 105.9 & 19.3 & 157.7 & 28.7 & 84.6 & 15.4 \\
$\mathrm{Ni}(650)$ & 175.7 & 27.0 & 183.3 & 28.2 & 198.2 & 30.5 & 145.7 & 22.4 \\
$\mathrm{~Pb}(1590)$ & 390.4 & 24.6 & 155.3 & 9.8 & 81.0 & 5.1 & 274.6 & 17.3 \\
$\mathrm{Zn}(2160)$ & 158.2 & 7.3 & 155.7 & 7.2 & 119.5 & 5.5 & 127.8 & 5.9 \\
\hline
\end{tabular}


dependent or only partially dependent on their respective formation constants (displayed in Table 2), since this is in the order of Ni-EDTA > Ni-EDDS > Ni-Acac. Clearly, other factors are also at play here.

For $\mathrm{Pb}$, the extraction efficiency did not follow the order of the column process and resembled that of the batch process, namely EDTA > CA $\gg$ EDDS > Hacac with an average efficiency of $14.2 \%$ (24.6 - 5.1), a bit lower than what was reported in the two previous processes. EDTA leached the most $\left(24.6 \mathrm{mg} \cdot \mathrm{kg}^{-1}\right)$ and Hacac leached the least $\left(5.1 \mathrm{mg} \cdot \mathrm{kg}^{-1}\right)$. The efficient removal of Pb by EDTA treatment can be explained considering the much higher stability constant of $\mathrm{Pb}$-EDTA $(\log K=18.8)$ if compared to the rest of the extractants (Pb-EDDS [ $\log K=12.7], \mathrm{Pb}-\mathrm{CA}[\log K=4.1]$ and $\mathrm{Pb}-\mathrm{Hacac}$ (for which no constant is available) [41] [47]. However, this presumption is not applicable for the percieved efficiency of CA over EDDS considering their formation constants. Such a result may be due to lower stability of Pb-EDDS complexes [48] or better still, the acid effect of the $\mathrm{CA}$, which can reduce the soil $\mathrm{pH}$ and form soluble complexes with $\mathrm{Pb}$ [35]. Hacac is less efficient for $\mathrm{Pb}$ recovery because of its poor stability complexes.

$\mathrm{Zn}$ extracted noticeably poorer with this process regardless of the extractants used. The extraction efficiency was similar in magnitude for all extractants used and was in the order EDTA $\approx$ EDDS $\approx \mathrm{CA} \approx$ Hacac, with an average efficiency of $6.5 \%$ (7.3 - 5.5) which is much less (about 3 -fold) than the other two processes. The low extraction efficiency of this process on $\mathrm{Zn}$ contaminated soil is in line with previous findings by Tandy [43] it can be said that in the case of $\mathrm{Zn}$, the extraction process is the main factor in determining its recovery.

Overall, it was further observed from Table 4 that EDTA $(25 \% \pm 15 \%)$ and EDDS $(22 \% \pm 15 \%)$ had similar efficiencies, calculated across the 5 metals of interest, and marginally outperformed the other extractants. The other extractants yielded $18 \% \pm 12 \%$ and $19 \% \pm 10 \%$ for Hacac and CA respectively.

\subsection{Comparison of the Three Processes}

To investigate the leaching process efficiency of the 5 metals of interest at three times their respective intervention concentrations from a SS, a static (batch) and two dynamic (column and heap) processes were investigated We appreciate that direct comparison between the three processes are influenced by technical and dynamic differences (for example, flow velocity variations, mass transfer effects), however, by keeping other parameters ( $\mathrm{pH}$, solid/liquid ratio) constant, an indirect comparison of the leaching tests could give insight in formulating a predictive leaching trend for the targeted metals released from a contaminated soil.

\subsubsection{Extractant Efficiency vs Metal Release}

In order to compare the potential to recover the metals of interest, using the 4 leaching agents (extractants) and the three different processes; the batch study (BS), column study (CS) and heap study (HS), data presented in Table 5 and Figure 1 were used. The important oservations will be noted for each metal in the section below. 


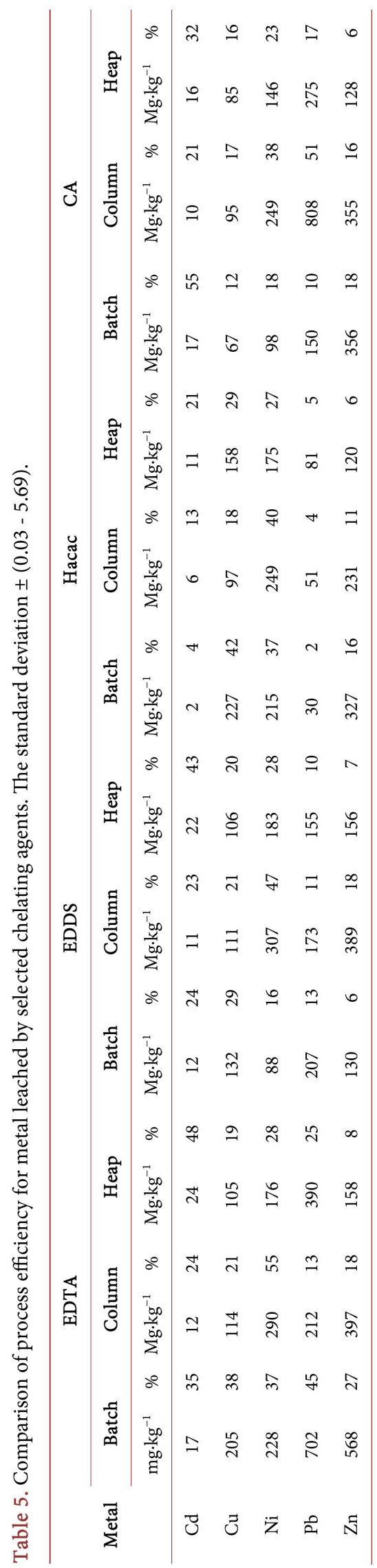



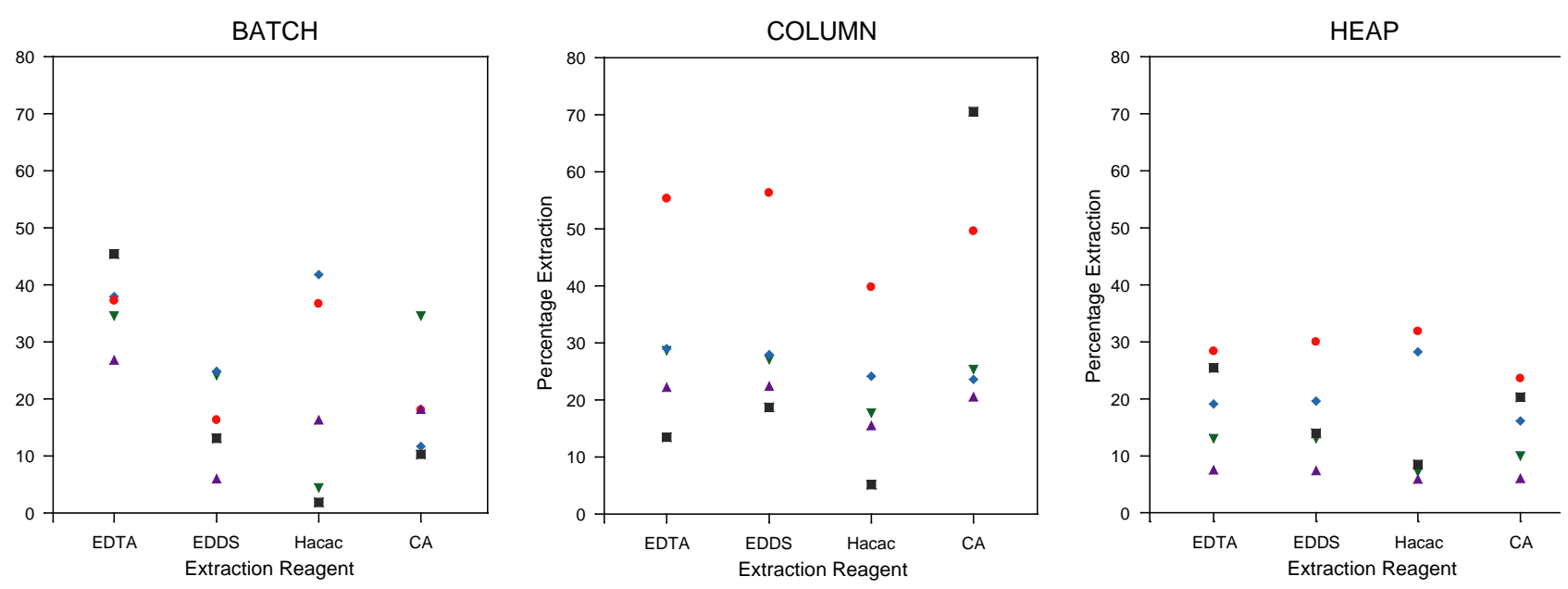

$\nabla \mathrm{Cd} \quad \mathrm{Cu} \quad \bullet \mathrm{Ni} \quad \square \mathrm{Pb} \quad \Delta \mathrm{Zn}$

Figure 1. Influence of the three process techniques (BS, CS, and HS) on the leaching efficiencies of metals of interest (Cd, Cu, Ni, $\mathrm{Pb}$, and $\mathrm{Zn}$ ) calculated across the four selected extractants (EDTA, EDDS, Hacac, and CA).

The efficiency trends of the three processes shown in Figure 1, displayed significant differential behaviour for the different metals extracted, as expected due to the different properties of metals and their different leaching mechanisms during soil washing [31]. The process efficiency for the three processes followed the order BS $\approx$ CS $>$ HS with average efficiency of $22.3 \%$ (range: $23.2-20.9$ ). The lower process efficiency exhibited by HS was also reported in literature [4] [49]. However, the process efficiencies of the CS and the BS were similar (calculated across the 4 extractants). This is contrary to a study reported by Hauser [50] where it was stated that column leaching, using a chelating agent (EDTA in their case), was better suited especially for $\mathrm{Zn}$ and $\mathrm{Pb}$ removal from contaminated soils.

Cd: The HS showed higher average process efficiency $(36.0 \% \pm 12 \%)$ taken across the extractants, than BS $(24.5 \% \pm 14.6 \%)$ and CS $(20.3 \% \pm 5.0 \%)$. It has to be borne in mind that a large variation in the data was observed. In the same vain, the highest efficiency is reported for leaching with EDTA. We can, therefore, conclude that $\mathrm{Cd}$ may be best extracted with EDTA using the heap process.

$\mathrm{Cu}: \mathrm{Cu}$ extraction was favoured by the BSwith average process efficiency across the extractants of $30.3 \% \pm 13.3 \%$, while the CS and the HS were $19.3 \% \pm$ $2.1 \%$ and $21 \% \pm 5.6 \%$, respectively. Table 5 also reveals that Hacac was the leaching agent that achieved the highest extraction efficiency.

$\mathrm{Ni}$ : The highest process efficiency, calculated across all leaching agents were for the CS and was $45 \% \pm 7.7 \%$, while the BS and HS were $27 \% \pm 11.6 \%$ and $26.6 \% \pm 2.4 \%$, respectively. The leaching agent providing the highest efficiency was EDTA. Therefore, the data suggested that a column leaching with EDTA will provide the best recovery for $\mathrm{Ni}$.

$\mathrm{Pb}$ and $\mathrm{Zn}$ : The average process efficiency for these two metals were the high- 
est with the BS and CS $\left(\mathrm{BS}_{\mathrm{Pb}} 17.5 \% \pm 18.9 \% ; \mathrm{CS}_{\mathrm{Pb}} 19.8 \% \pm 21.2 \%\right)$ and $\left(\mathrm{BS}_{\mathrm{Zn}}\right.$ $\left.16.8 \% \pm 8.6 \% ; \mathrm{CS}_{\mathrm{Zn}} 15.8 \% \pm 3.3 \%\right)$. For $\mathrm{Pb}$ the highest extraction efficiency was with CA and for $\mathrm{Zn}$ with EDTA. This suggests that $\mathrm{Pb}$ be best extracted by column percolation and CA, while $\mathrm{Zn}$ would be best with the batch process and EDTA.

\subsubsection{Extractant Efficiency vs Process Used}

In order to compare the influence of the 4 leaching agents (extractants) on the process efficiency of the batch study (BS), column study (CS) and heap study (HS), the data presented in Table 5 and Figure 2 are used.

Figure 2 provides a graphical data summary, including the median, quartiles, skewness of distribution as well as the mean percentage extraction in a comparison of the different processes (BS, CS, and HS) studied. The data were averaged over all the metals. It is first noticed that the HS showed the most variation for EDTA and EDDS, but for Hacac and CA the variation was most for the BS and CS, respectively. For the EDTA plot, each of the operations illustrated different trends in skewness pattern. The batch operation is skewed to the left, the heap operation is skewed to the right, and the column operation appeared to be literally symmetric.

The EDDS plot showed similar trends than the EDTA except that the average efficiency for the BS was lower. Hacac as leaching agent showed the largest 50 percentile variation for the batch process data, which may point to lower confidence as a predictive tool. On the other hand, large variability lends itself to selective leaching. The three processes are skewed to the right. The mean values for the batch $(20.3 \%)$ and HS (21.2\%) were comparable while CS (14.2\%) differed by a factor of 1.5 For CA, both the column and heap systems were skewed to the right as well as displayed larger variability when compared to the batch system that literally remained symmetric with minimal variability. However, the BS had a mean value of only $8.6 \%$, while the HS (32.4\%) and CS (24.2\%) were significantly more efficient.

Following the extraction trends, the data suggests that EDTA on average provides the highest extraction efficiency across all metals, using the heap leaching process. Due to the large variations observed across the metals for each of the leaching agents for one or two of the processes, selective leaching can be achieved by designing a multi-step contaminant specific process.

\section{Conclusion}

The effect of three different leaching processes and four different leaching extractants on the extraction of five metals of interest from an artificially contaminated simulated soil has been evaluated. The batch study in this context revealed that for artificially contaminated SS, the best extractant across all the metals investigated was EDTA. Cd could be extracted with CA to the same efficiency as EDTA but showed much lower efficiencies for all other metals. Similarly, $\mathrm{Cu}$ and $\mathrm{Ni}$ reported slightly higher efficiencies with Hacac using this process. The column process revealed that extraction efficiency of $\mathrm{Pb}$ with $\mathrm{CA}$ was highest in 

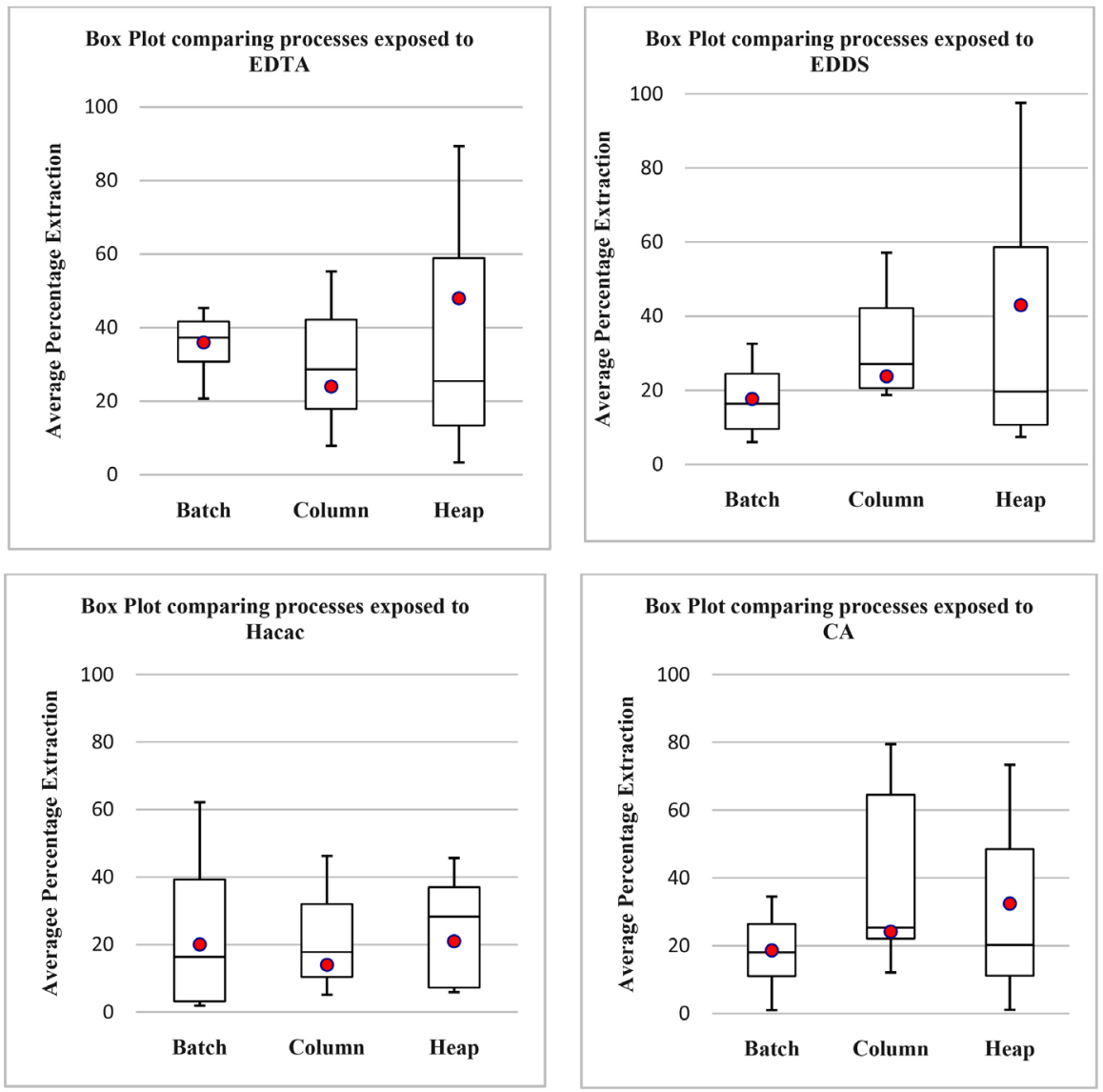

Figure 2. Box plots comparing BS, CS, and HS processes for percentage metal $(\mathrm{Cd}, \mathrm{Cu}$, $\mathrm{Ni}, \mathrm{Pb}, \& \mathrm{Zn}$ ) leaching using selective solvent reagents calculated across 5 metals. The lines inside the boxes represent the median values; the red dots represent the mean values; and the lower and upper boundaries of the box indicate 25 and 75 percentiles of the sample size $(\mathrm{n}=5)$.

comparison to all other process and extractants used. Ni showed preferential recovery with Hacac and was comparable to the recovery using batch method. In the heap process, Cd was recovered with the highest efficiency when compared to BS and CS. Overall the leaching test results have demonstrated that the recovery of the five metals was significantly and differently influenced by both the leaching agents, as well as the leaching process. Therefore, an efficient selective leaching process could be attained if a multi-step contaminant specific process for a full-scale recovery purpose is designed.

\section{Conflicts of Interest}

The authors declare no conflicts of interest regarding the publication of this paper.

\section{References}

[1] Kesler, S.E. (2010) Geological Stocks and Prospects for Non-Renewable Resources, in Linkages of Sustainability. The MIT Press, Cambridge, 109-129. 
https://doi.org/10.7551/mitpress/9780262013581.003.0007

[2] Gordon, R.B., Bertram, M. and Graedel, T.E. (2006) Metal Stocks and Sustainability. Proceedings of the National Academy of Sciences of the United States of America, 103, 1209-1214. https://doi.org/10.1073/pnas.0509498103

[3] Henckens, M.L.C.M., Driessen, P.P.J. and Worrell, E. (2016) The Sustainable Extraction of Primary Zinc and Molybdenum. An Investigation of Measures to Reduce Primary Zinc and Molybdenum Use to a Sustainable Level.

[4] Brierley, C.L. (2008) How Will Biomining Be Applied in Future. Transactions of Nonferrous Metals Society of China, 18, 1302-1316. https://doi.org/10.1016/S1003-6326(09)60002-9

[5] Kostov, A., Dimitrijević, M., Tasić, V. and Milosević, N. (2008) Influence of Pyrometallurgical Copper Production on the Environment. Journal of Hazardous Materials, 164, 892-889. https://doi.org/10.1016/j.jhazmat.2008.08.099

[6] Sapsford, D., Cleall, P. and Harbottle, M. (2016) In Situ Resource Recovery from Waste Repositories: Exploring the Potential for Mobilization. Journal Sustainable Metallurgy, 3, 375-392. https://doi.org/10.1007/s40831-016-0102-4

[7] Johansson, N., Krook, J. and Eklund, M. (2013) An Integrated Review of Concepts and Initiatives for Mining the Technosphere: Towards a New Taxonomy. Journal of Clean Production, 55, 35-44. https://doi.org/10.1016/j.jclepro.2012.04.007

[8] EEA (2007) State of the Environment Report No. 1/2007 Europe's Environment-The Fourth Assessment. European Environmental Agency, Copenhagen.

[9] Dermont, G., Bergeron, M., Mercier, G. and Richer-Lafleche, M. (2008) Soil Washing for Metal Removal: A Review of Physical/Chemical Technologies and Field Applications. Journal of Hazardous Materials, 152, 1-31. https://doi.org/10.1016/j.jhazmat.2007.10.043

[10] Anikwe, M.A.N. and Nwaobodo, K.C.A. (2002) Long Term Effect of Municipal Waste Disposal on Soil Properties and Productivity of Sites of Nigeria. Bioresource Technology, 83, 241-250. https://doi.org/10.1016/S0960-8524(01)00154-7

[11] Odewande, A.A. and Abimbola, A.F. (2008) Contamination Indices and Heavy Metal Concentrations in Urban Soil of Ibadan Metropolis, Southwestern Nigeria. Environmental Geochemistry and Health, 30, 243-254. https://doi.org/10.1007/s10653-007-9112-2

[12] Hultman, J. and Corvellec, H. (2012) The European Waste Hierarchy: From the Sociomateriality of Waste to a Politics of Consumption. Environmental Planning, 44, 2413-2427. https://doi.org/10.1068/a44668

[13] Sadhukhan, J., Ng, K.S. and Martinez-Hernandez, E. (2016) Novel Integrated Mechanical Biological Chemical Treatment (MBCT) Systems for the Production of Levulinic Acid from Fraction of Municipal Solid Waste: A Comprehensive Techno-Economic Analysis. Bioresource Technology, 215, 131-143. https://doi.org/10.1016/j.biortech.2016.04.030

[14] Grathwohl, P. and Susset, B. (2009) Comparison of Percolation to Batch and Sequential Leaching Tests: Theory and Data. Waste Management Journal, 29, 2681-2688. https://doi.org/10.1016/j.wasman.2009.05.016

[15] Jackson, D.R., Garrett, B.C. and Bishop, T.A. (1984) Comparison of Batch and Column Methods for Assessing Leachability of Hazardous Waste. Environmental Science and Technology, 18, 668-673. https://doi.org/10.1021/es00127a007

[16] Garrabrants, A.C. and Kosson, D.S. (2005) Leaching Processes and Evaluation Tests 
for Inorganic Constituent Release from Cement-Based Matrices. In: Spence, R. and Shi, C., Eds., Stabilization and Solidification of Hazardous, Radioactive and Mixed Waste, CRC Press, Boca Raton, 229-280. https://doi.org/10.1201/9781420032789.ch10

[17] Al-Abed, S.R., Jegadeesan, G., Purandare, J. and Allen, D. (2008) Leaching Behaviour of Mineral Processing Waste: Comparison of Batch and Column Investigations. Journal of Hazardous Materials, 153, 1088-1092.

https://doi.org/10.1016/j.jhazmat.2007.09.063

[18] Ham, R.K., Anderson, M.A., Stanforth, R. and Stegmann, R. (1979) Background Study on the Development of a Standard Leaching Test. United States Environmental Protection Agency, Washington DC, EPA/600/2-79/109 (NTIS PB298280).

[19] van der Sloot, H.A., van Zomeren, A., Dijkstra, J.J., Hoede, D., Jacobs, J. and Scharff, H. (2003) Prediction of Long Term Leachate Quality and Chemical Speciation for a Predominantly Inorganic Waste Landfill. 9th International Waste Management and Landfill Symposium, Santa Margherita di Pula, 6-10 October 2003, 36-38.

[20] Kendall, D.S. (2003) Toxicity Characteristic Leaching Procedure and Iron Treatment of Brass Foundry Waste. Environment, Science and Technology, 37, 367-371. https://doi.org/10.1021/es020621n

[21] Wasay, S.A. (1992) Leaching Study of Toxic Trace Elements from Fly Ash in Batch and Column Experiment. Journal of Environmental Science and Health A, 27, 697-712. https://doi.org/10.1080/10934529209375755

[22] Dijkstra, J.J., van der Sloot, H.A., Meeussen, J.C.L. and Comans, R.N.J. (2006) Local Chemical Equilibrium Makes Column Test Protocol TS14405 Suitable for Model Predictions. 6th International Conference on the Environmental and Technical Implications of Construction with Alternative Materials Science and Engineering of Recycling for Environmental Protection, Belgrade, 30 May-2 June, 2006, 345-348.

[23] Potgieter-Vermaak, S.S., Mgbeahuruike, L.U., van Dyk, L., Barret, J. and Potgieter, J.H. (2017) Predictive Potential of Individual Soil Components on the Leaching Behaviour of Metal Contaminants from a Simulated Soil.

[24] OECD (1984) Earthworm, Acute Toxicity Tests. OECD Guidelines for Testing of chemicals, Organisation for Economic Cooperation and Development, Paris, Test No. 207.

[25] ISO (1998) Soil Quality: Effects of Pollutants on Earthworms (Eisenia fetida). Part 2: Determination of Effects on Reproduction.

[26] DPR (Department of Petroleum Resources) (2002) Environmental Guidelines and Standards for the Petroleum Industry in Nigeria.

[27] Roman, R.J., Benner, B.R. and Becker, G.W. (1974) Diffusion Model for Heap Leaching and Its Application to Scale-Up. Transactions of the Society of Mining Engineers, 256, 247-252.

[28] Schlitt, W.J. (2006) History of Forced Aeration in Copper Sulphide Leaching. SME Annual Meeting, 27-29 March 2006, St. Louis, MO, 6-17.

[29] Soil Conservation Services USDAH (1975) Soil Taxonomy, a Basic System of Soil Classification for Making and Interpreting Soil Surveys. Soil Survey Staff Report, Government Printing Office, Washington DC.

[30] Chen, M., Xu, P., Zeng, G., Yang, C., Huaug, D. and Zhang, J. (2015) Bioremediation of Soil Contaminated with Polycyclic Aromatic Hydrocarbons, Petroleum, Pesticides, Chlorophenols and Heavy Metals by Composting: Applications, Microbes 
and Future Research Needs. Biotechnology Advancement, 33, 745-755. https://doi.org/10.1016/j.biotechadv.2015.05.003

[31] McGrath, S.P., Sun, B., Zhao, F.J. and Lombi, E. (2001) Leaching of Heavy Metals from Contaminated Soils Using EDTA. Environmental Pollution, 113, 111-120. https://doi.org/10.1016/S0269-7491(00)00176-7

[32] Kordosky, G.A. (1992) Copper Solvent Extraction: The State of the Art. Journal of Metals, 44, 40-45. https://doi.org/10.1007/BF03223049

[33] Kovo, G.A., Folasegun, A.D. and Kayode, O.A. (2015) Mechanism on the Sorption of Heavy Metals from Binary Solution by a Low Cost Montmorillonite and Its Desorption Potential. Alexandria Engineering Journal, 54, 757-767. https://doi.org/10.1016/j.aej.2015.03.025

[34] Zaleckas, E., Paulauskas, V. and Sendzikiene, E. (2013) Fractionation of Heavy Metals in Sewage Sludge and Their Removal Using Low Molecular Weight Organic Acids. Journal Environmental Engineering Landscape Management, 21, 189-198. https://doi.org/10.3846/16486897.2012.695734

[35] Evangelou, M.W.H., Ebel, M. and Schaeffer, A. (2007) Chelate Assisted Phytoextracton of Heavy Metals from Soils. Effect, Mechanism, Toxicity and Fate of the Chelating. Chemosphere, 68, 989-1003. https://doi.org/10.1016/j.chemosphere.2007.01.062

[36] Peters, R.W. (1999) Chelant Extraction of Heavy Metals from Contaminated Soils. Journal of Hazardous Materials, 66, 151-210. https://doi.org/10.1016/S0304-3894(99)00010-2

[37] Sánchez-Chacón, A.E. and Lapidus, G.T. (1997) Model for Heap Leaching of Gold Ores by Cyanidation. Hydrometallurgy, 44, 1-20. https://doi.org/10.1016/S0304-386X(96)00052-7

[38] Xie, T. and Marshall, W.D. (2001) Approaches to Soil Remediation by Complexometric Extraction of Metal Contaminants with Regeneration of Reagents. Journal Environmental Monitoring, 3, 411-416. https://doi.org/10.1039/b009876k

[39] Steele, M.C. and Pichtel, J. (1998) Ex-Situ Remediation of a Metal-Contaminated Superfund Soil Using Selective Extractants. Journal Environmental Engineering-American Society of Chemical Engineers, 124, 639-645. https://doi.org/10.1061/(ASCE)0733-9372(1998)124:7(639)

[40] Podyachev, S.N., Sudakova, S.N., Galiev, A.K., Mustafina, A.R., Syakaev, V.V., Shagidullin, R.R., Bauer, I. and Konovalou, A.I. (2006) Synthesis of Tris and Study of Their Complexation with Some Transition Metals. Russian Chemical Bulletin, International Edition, 55, 2000-2007. https://doi.org/10.1007/s11172-006-0542-2

[41] Orama, M., Hyvönen, H. and Saarinen, H.A.R. (2002) Complexation of [S,S] and Mixed Stereoisomers of N'N-ethylenediaminedisuccinic Acid (EDDS with F(III), $\mathrm{Cu}$ (II), Zn (II) and M (II) Ions in Aqueous Solution. Journal of the Chemical Society Dalton Transactions, 24, 4644-4648. https://doi.org/10.1039/B207777A

[42] Tsang, D.W.C., Yip, T.C.M. and Lo, I.M.C. (2009) Kinetic Interactions of EDDS with Soils. 2. Metal-EDDS Complexes in Uncontaminated and Metal-Contaminated Soils. Environmental Science Technology, 43, 837-842. https://doi.org/10.1021/es8020292

[43] Tandy, S., Bossart, K., Mueller, R., Ritschel, J., Hauser, L., Schulin, R. and Nowack, B. (2004) Extraction of Heavy Metals from Soils Using Biodegradable Chelating Agents. Environment Science Technology, 38, 937-944. https://doi.org/10.1021/es0348750

[44] Schecher, W.D. and McAvoy, D.C. (2001) MINEQL+: A Chemical Equilibrium 
Modelling System, Version 4.5 for Windows. Environmental Research Software, Hallowell.

[45] Koopmans, G.F., Schenkeveld, W.D.C., Song, J., Luo, Y., Japenga, J. and Temminghoff, E.J.M. (2008) Influence of EDDS on Metal Speciation in Soil Extracts: Measurement and Mechanistic Multicomponent Modelling. Environmental Science Technology, 42, 1123-1130. https://doi.org/10.1021/es071694f

[46] Elliot, H.A. and Shastri, N.L. (1999) Extractive Decontamination of Metal-Polluted Soils Using Oxalate. Water, Air and Soil Pollution, 110, 335-346. https://doi.org/10.1023/A:1005067404259

[47] Martell, A.E. and Smith, R.M. (2003) NIST Critically Selected Stability Constants of Metal Complexes. Version 7.0, NIST, Gaithersburg.

[48] Yip, T.C.M., Yan, D.Y.S., Yui, M.M.T., Tsang, D.C.W. and Lo, I.M.C. (2010) Heavy Metal Extraction from an Artificially Contaminated Sandy Soil under EDDS Deficiency: Significance of Humic Acid and Chelant Mixtures. Chemosphere, 80, 416-421. https://doi.org/10.1016/j.chemosphere.2010.03.033

[49] Acevedo, F. (2002) Present and Future of Bioleaching in Developing Countries. Electronic Journal of Biotechnology, 52, 56.

https://doi.org/10.2225/vol5-issue2-fulltext-10

[50] Nowack, B., Hauser, L., Tandy, S. and Schulin, R. (2005) Column Extraction of Heavy Metals from Soils Using the Biodegradable Chelating Agent EDDS. Environmental Science Technology, 39, 6819-6824. https://doi.org/10.1021/es050143r 